\title{
The Ticking Mind and Beating Heart: Speaking, Imagination and Empathic Intelligence
}

\author{
Fateme Esmaili \\ Department of English language and literature, Arak University, Arak, Iran \\ Somaye Hamdi Asl \\ Department of English language and literature, Azad University of Najafabad, Najafabad, Iran
}

Elham Farahani

Department of English language and literature, Arak University, Arak, Iran

\begin{abstract}
This study was an attempt to investigate the nature of inter-subjective and intra-subjective phenomena in terms of the interface between language, thought, feelings as well as the relationships between teachers and students. In effect, this study discusses the mentioned issues by focusing on the argument that a sensitive attention should be given to the embodied language experiences brought by students into the class in order to demystify the discourse experiences which enhance or impede students' language progress. To this end, an eclectic model has been designed and developed based on some particular principles suggested by different approaches in CDA along with emphatic intelligence. Hence, a number of advanced Iranian students learning English as a foreign language were selected as the participants of the study who went under a 120hour instruction. The study revealed that in teaching speaking skill, a kaleidoscopic view needs to be adopted in terms of the relation between and among the interlocutors in which the social relations seem to be crucial.
\end{abstract}

Index Terms - critical discourse analysis, emphatic intelligence, inter-subjectivity, intra-subjectivity, kaleidoscopic view

\section{INTRODUCTION}

Speaking skill is one of the most challenging issues language learners have to deal with. Speaking proficiency seems to be one of the main priorities for language learners. In fact, language learners tend to evaluate their progress in English through their speaking skill. It is worth mentioning that oral skills in general and speaking skill in particular have been the focus of almost all language textbooks through conversations or pair works. In effect, a variety of approaches, according to Richards (1990), have been resorted to in dealing with speaking (e.g. direct approach in which some particular features of oral interaction are elaborated like turn taking, topic management or oral strategies; and also indirect approach in which the attention is directed to conditions, context, or task work as well as group work, etc.).

McCarthy and Carter (1997) argued that so many attentions have been directed to oral proficiency which revealed that the nature of speaking is totally different from that of writing. McCarthy and Carter (1997) continued that the observed differences are depicting the purposes of choosing writing or speaking mediums for communication.

Spoken discourse, according to Luoma (2004), is composed of conjoined phrases and clauses, planned and unplanned speech, laden with more vague and generic vocabularies, fixed phrases, fillers or hesitation markers, slips and errors, and are formal or casual.

Considering the fact that a comprehensive language learning takes place in a situation in which diverse dimensions are developed; a blended and eclectic model seems to be conceivable since speaking as a challenging skill involves a vast variety of factors-productivity, purposefulness, interactivity, challenge and authenticity besides vocabulary, structural and phonological accuracy. Hence, speaking as a skill means a particular combination of critical thinking, imagination, body language, vocabulary, structure, stress, intonation, voice, etc. Hence, among different involved factors in speaking skill, three factors of critical thinking, imagination and emphatic intelligence are worthy to be reflected.

Resorting to the inter-subjective and intra-subjective nature of language learning; using five models of CDA, an interface was made between language, thought, and feelings. In effect, the presents study by considering the relationship between teacher and students as well as the embodied language experiences brought by students into the class tries to design a framework in teaching speaking skill to enhance students' speaking proficiency. To this end, an eclectic model has been designed and developed based on the particular principles suggested through Fairclough's (2001) three-dimensional model, Van Dijk's (2001) sociocognitive model, Jäger's (2001) discourse and dispositive model, Wodak's (2001) historical model, as well as Scolon's (2001) mediated discourse analysis model. It is worth mentioning that the adopted model based on which the study was conducted developed through blending some particulars of different approaches in CDA along with emphatic intelligence as the best method to meet the needs of the 
study. The following sheds light on the concepts crucial in conducting the present study, i.e. CDA, emphatic intelligence, as well as speaking skill, teachers and learners.

\section{REVIEW OF LITERATURE}

\section{A. Critical Discourse Analysis: Theoretical Definition}

Critical discourse analysis (CDA) is an academic research activity aiming to investigate "the power relations, ideological manipulations, and hegemony" (Rahimi \& Sahragard, 2007, p.1). CDA indicates what has been formerly known as critical linguistics (CL) (Wodak, 2002) which emerged in the late 1970s (Fowler and Kress, 1979). Critical theory provides a critical perspective or attitude towards society (Rahimi \& Sahragard, 2007). Fairclough (1995) defines critical theory as "any theory concerned with critique of ideology and the effects of domination" (p.20).

Systemic functional linguistics (SFL) which was introduced by Halliday is the basic ground for CL or nowadays CDA. It is a theory of grammatical description that considers language as a semiotic system. This theory recognizes several strata for language. The description part of this theory seeks to provide a general grammar applicable to text analysis as well as in the interpretation of the text (Webster, 2003). SFL has different but inter-related functions (Halliday, 1985). Halliday (1985, p. XXVI) presents SFL as:

(...) a theory of language as choice. It represents a language, or any part of language, as a resource for making meaning by choosing. Each choice point in the network specifies (1) an environment, consisting of choices already made, and (2) a set of possibilities of which one is (to be ) chosen; (1) and (2) taken together constitute a 'system' in this technical sense (...)

Hence, CDA embarks on deciphering and demystifying both "opaque and transparent structural relationships of dominance, discrimination, power and control" (Wodak, 2007, pp.208-209). Wodak (2001) argued that "CDA sees language as 'social practice' (p. 1), and considers the context of language use to be crucial (Weiss and Wodak, 2003). She assumed three concepts of critique, power, history and ideology as indispensable elements in all CDA.

Wodak (2001) elaborates that the main purpose of CDA is revealing "the opacities in discourse which contribute to the exercise, maintenance, or reproduction of unequal relations of power" (p.258). It means that the ambiguous utterances are elucidated in order to uncover the unequal power structures governing the society.

$\mathrm{CDA}$ as a new paradigm in the domain of applied linguistics has been so thriving that most studies are now conducted based on its principles. Students bring their experiences of language, communication, culture, personal issues and even their emotional feelings, their knowledge of the world, of language, etc. It seems that CDA may suggest some procedures or principles adapting into real language context especially for enhancing speaking and resolving the observed challenges. Yet, the role played by emotions and feelings cannot be ignored. There is compelling evidence for blending speaking skill with emphatic intelligence and imagination. In fact, CDA may be beneficial in enhancing oral proficiency through blending and modeling imagination, emphatic intelligence and different skills of language in general and speaking skill in particular.

\section{B. Emphatic Intelligence}

One of the issues worth mentioning is related to the fact that effective teaching and learning needs to occur in an emotional along with intellectual context where individuals' personal experiences, value systems, skills, abilities and even the emotional and intellectual challenges the students go through were considered. Arnold (1991, 1993, 1994, \& 1998) argued that effective teaching occurs in a dynamic situation in which thoughts and feeling were reconciled through the relations between teacher and students.

Hence, emphatic intelligence seems to be a crucial factor influences the performances of the teachers since, it refers to the capacity by which the students are stimulated to engage in the process of learning along with the enthusiasm and expertise it provides for the teacher. In other words, the concept of emphatic intelligence highlights a liberal, democratic, student-centered educational paradigm which emerged during 1960s by John Dewey.

In effect, emphatic intelligence refers to a concept through which inter-subjectivity (dynamic relations between subjects) and intra-subjectivity (dynamic experiences within the subjects) are expressed (Arnold, 1993). Arnold (1993) considers inter-subjectivity and intra-subjectivity as the influential factors for learning. Hence, emphatic intelligence refers to the capacity to adjust oneself towards others, to reflect oneself and to mirror others. In effect, Arnold considers emphatic intelligence as an intelligently caring context.

\section{METHODOLOGY}

The aim of the present study was to design and develop an innovative model in order to resolve the difficulties the learners go through in achieving a satisfactory proficiency in using speaking skill. In fact, the study aimed to examine the potentials of an eclectic model of CDA to improve the speaking proficiency of Iranian EFL students. This study involved both quantitative and qualitative analyses, but the overall design of this investigation was a qualitative position.

\section{A. Research Questions}

The following research questions were posed about the two groups of learners (experimental and control): 
1. What are the differences between the performances of students who went under instruction through the designed innovative model and those who went under instruction through the usual model?

2. What are the differences between the performances of the subjects before and after instruction?

\section{B. Participants}

The participants of the present study were 60 advanced language learners from two intact classes of a language institutes in Shiraz (Farda Language Institute), with 30 students in each (15 females and 15 males), i.e. experimental group and control group. The classes were held for six two-hour sessions per week for a total of 120 hours over 10 weeks. Therefore, during the course, diverse themes and topics were covered (Family; Education; Jobs; Hobbies and interests; Hometown; Transportation; Shopping; Television; Gifts; Travel; Success; Adventure; Food; fashion). The experimental group went through an eclectic model but the control groups went through a traditional method of teaching speaking.

\section{Method}

In conducting the present study an eclectic model was selected and adopted based on the particular principles suggested by Fairclough's (2001) three-dimensional model, Van Dijk's (2001) sociocognitive model, Jäger's (2001) discourse and dispositive model, Wodak's (2001) historical model, as well as Scolon's (2001) mediated discourse analysis model along with the emphatic intelligence. In effect, considering the concept of discourse planes introduced by Jager (2001), which refers to " the societal locations from which `speaking' happens" (Jager, 2001, p. 49), the present study assumed the discourse planes as the diverse genres like science(s), politics, media, education, everyday life, business life, administration, etc. which is working as an umbrella contains other factors.

To this end, borrowing from Jager (2001), the concept of discourse position as a sub-category of discourse plane was assumed as "the specific ideological location of a person or a medium (Jager, 2001, p. 49). Jager (1996) defines discourse position as the location from which the participation in the discourse and assessment of it for individuals and/or groups and institutions result. It produces and reproduces the special discursive entanglements, which feed on the hitherto experienced and current life situation of those involved in the discourse. Thus, the discourse position is the result of the involvement in, of being 'knitted into', various discourses to which the individual has been subjected and which it has processed into a certain ideological position during the course of its life. (p. 47)

in operationalizing the model, the discourse position were supposed to be composed of the four elements of nexus of practice, mediated means, social relations and cultural values which seems to be crucial in any speaking task.

Furthermore, the students were exposed to diverse topics which is based on the semantic macro-structure of the adopted model in which practice, genre, discourse fragments or texts and emphatic intelligence were crucial. The following diagram shows the designed model in teaching speaking to the experimental group.

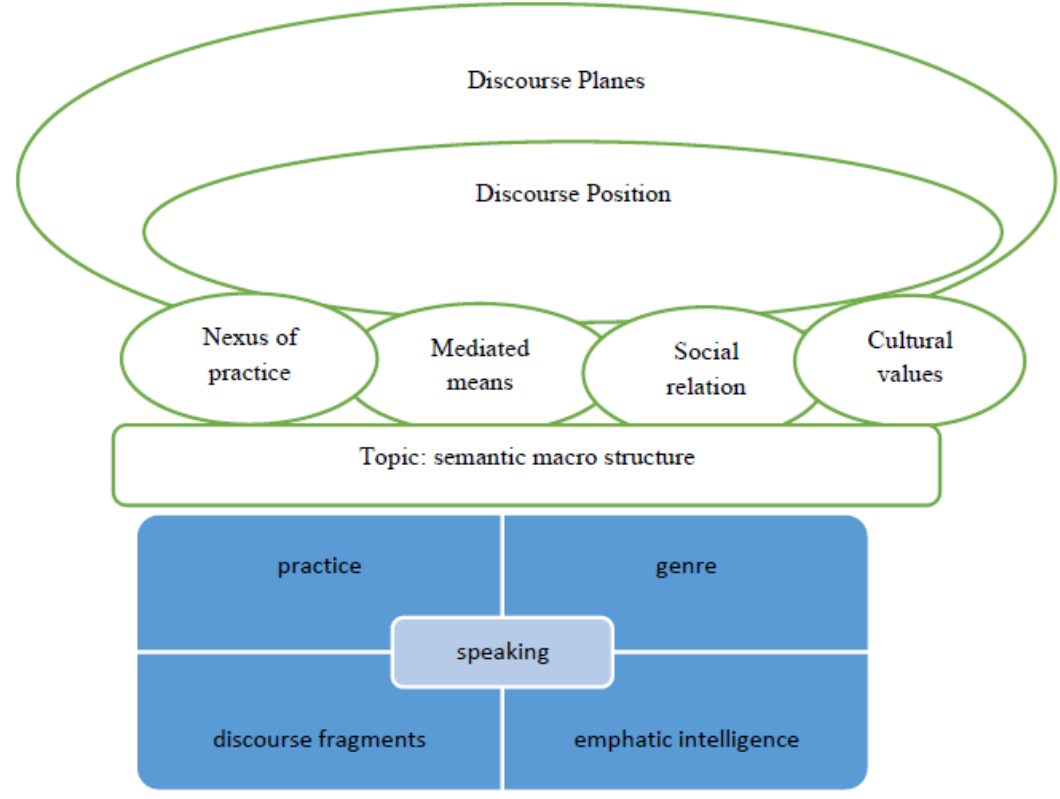

Generally, in evaluating the speaking skill of the learners, their performance were measured based on three macrofeatures of mechanics, functions as well as social and cultural rules and norms. Mechanics composed of pronunciation, grammar, and vocabulary; functions of transaction and interaction; and social and cultural rules and norms of turntaking, rate of speech, length of pauses between speakers and relative roles of participants.

\section{Procedure}


In conducting the present study two homogenous groups of EFL learners studying English at the advanced levelwho were studying English for at least 5 years were selected as the participants of the study. In effect, the participants were 60 homogenous students with 30 students in each group - an experimental and a control group each composed of 15 females and 15 males. Hence, the control group received instruction using a traditional approach common in handling speaking tasks in Iran-pre-speaking for warm-up, during-speaking to handle the speaking task, and postspeaking phase in which the students discuss other related issues along with the tips provided by the teacher in terms of supra-segmental features, accuracy (grammatical errors), idioms, expressions, etc. the experimental group, on the other hand, were taught using the eclectic model in which not only their critical thinking were raised but also their emphatic intelligence, the different elements of any speaking task, i.e. cultural values, social relations, mediated means, nexus of practice (body language, eye-contact, language itself, etc.), discourse planes and positions along with genres were considered and dealt with. It is worth mentioning that the two groups went through a pre-test and a post-test based on IELTS speaking to determine their progress and effectiveness of the course. In effect, in both pre- and post-tests an analytic procedure were utilized in scoring. Finally the extracted data were analyzed and compared between and among groups.

Practically, in teaching speaking, the students in the control group went through five micro-stages, i.e. warm-up (15 minutes), presenting useful expressions (15 minutes), asking questions based on the presented topic (30 minutes), vocabulary expansion (20 minutes), and focus point (40 minutes). It is worth mentioning that the subjects were informed about the next topic which would be covered in the next session. The experimental group, on the other hand, not only received instruction in the same order with the same allocated time in each micro-phase but also were consciously raised in terms of the genres of the speaking tasks the students went through, the various discourses through which the speaking tasks might be handled, the role played by body language, eye contact, social relations and cultural values through role playing. In addition, the emphatic intelligence of the experimental group were considered and handled in terms of inter-subjective and intra-subjective dimensions in which the thoughts, feeling and ideas of the subjects were influencing and influenced. In other words, the discussion-like class encouraged the students to share their own feelings, thoughts, and ideas in such a way that they forgot their concerns about accuracy while trying to express their own thoughts, feeling and ideas. It is worth mentioning that the situation in which the students tried to win the floor were achieved through raising their critical thinking and critical attitude using challenging questions.

Yet, both the pre-test and post-test on the speaking proficiency of the subjects were scored analytically in four domains of fluency and cohesion, lexical resources, grammatical range as well as accuracy and pronunciation with a band score of zero to four (0-4). The results were put in SPSS 15 to be analyzed and compared. The next parts sheds light on the results.

\section{RESUlts}

Descriptive statistics including means and standard deviation of the both experimental and control groups in the prespeaking are given in Table 1 .

TABLE 1:

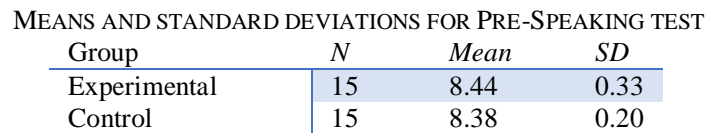

Table 1 illustrates that the participants of the study were 30 students studying English in institutes for several years who were divided into two groups of experimental and control randomly. In effect, the table shows the performance of students in pre-speaking test, in which, the mean of the scores of the experimental group was 8.44 and of the control group 8.38. Furthermore, participants showed a standard deviation of 0.33 in the experimental group and 0.20 in the control group. In order to determine the homogeneity of the two groups of experimental and control, the scores of the participants in the two groups were put in the SPSS software and the t-test statistic for independent samples was run which was resulted in the homogeneity between the two groups and non-significance differences between them. The following tables illustrate the results of the t-test on the pre-speaking test.

TABLE 2:

T-TEST ON THE RESULTS OF THE PRE-SPEAKING TEST: EXPERIMENTAL VS. CONTROL GROUPS

\begin{tabular}{lllll}
\hline & Sig. & t & df. & Mean difference \\
Scores & 0.55 & 0.59 & 23.21 & 0.06 \\
\hline
\end{tabular}

As table 2 shows the significance of conducting the t-test is 0.59 , well above the 0.05 threshold, so the two groups of experimental and control are homogenous in terms of speaking proficiency before the instruction. In the previous section, it was discussed that the two groups went through a 120-hour course on speaking followed by a post-speaking test. Table 3 shows the performance of students in post-speaking test, in which, the mean of the scores of the experimental group was 12.85 and of the control group 12.05. Furthermore, participants showed a standard deviation of 0.38 in the experimental group and 0.46 in the control group. 
TABLE 3:

\begin{tabular}{l|lll}
\multicolumn{4}{c}{ MEANS AND STANDARD DEVIATIONS FOR POST-SPEAKING TEST } \\
Group & $N$ & Mean & SD \\
\hline Experimental & 15 & 12.85 & 0.38 \\
Control & 15 & 12.05 & 0.46
\end{tabular}

The scores given to the students on the post-speaking test were also put in the SPSS software in order to have a comparison between the performances of the two groups besides the progress the students had after the instruction. Table 4 sheds light on the differences between the performances of the two groups of experimental and control after instruction.

TABLE 4:

T-TEST ON THE RESULTS OF THE POST-SPEAKING TEST: EXPERIMENTAL VS. CONTROL GROUPS

\begin{tabular}{lllll}
\hline & Sig. & t & df. & Mean difference \\
\hline Scores & 0.00 & 5.11 & 26.90 & 0.79 \\
\hline
\end{tabular}

As the table shows (table 4) the significance of conducting the t-test is 0.00 , under the cut-off point of 0.05 ; accordingly, there is evidence to suggest that participants in the experimental group experienced statistically significantly greater progress due exposing the innovative method for speaking comparing to the results achieved by the participants in the control group.

Furthermore, the paired sample t-test was conducted to determine whether the progress of the two groups before and after instruction is significant or not. In effect, the paired t-test was conducted to evidentially investigate the effects of the instructional course on the improvement of the subjects. The results are presented in table 5 .

TABLE 5:

\begin{tabular}{|c|c|c|c|c|}
\hline Pre-speaking-post-speaking & Sig. & $\mathbf{t}$ & df. & Mean difference \\
\hline Experimental group & 0.00 & -30.86 & 14 & -4.40 \\
\hline Control group & 0.00 & -32.61 & 14 & -3.67 \\
\hline
\end{tabular}

The results in table 5 indicated that the differences between the performances of the participants in the pre-speaking and post-speaking tests in the both groups were significant. In other words, the instructional course was successful in improving the speaking proficiency of the subjects. Hence, there is no doubt regarding the efficacy of the presented instructional course to improve the speaking proficiency; but, it seems that the eclectic innovative model in teaching the speaking proficiency-resorting to the some principles of the critical discourse analysis approach, imagination, and empathic intelligence-was more successful.

\section{FINDINGS AND IMPLICATIONS}

The results and the related data demonstrated the supremacy of experimental group who went through instruction based on an innovative model utilizing some concepts and terminologies of CDA along with the ones of emphatic intelligence as well as imagination. However, the both groups were homogeneous in terms of the speaking proficiency on the outset; the results of t-test statistic indicted to the significant differences between the both groups of experimental and control. In effect, the results showed the homogeneity between the two groups in terms of speaking proficiency before instruction but the observed differences between the two groups in terms of speaking profanely after the instruction revealed something about the role played by method of instruction on speaking.

In effect, some principles or even terminologies of the critical discourse analysis supported by a number of models were utilized in designing, developing and implementing an innovative model merged with the foundations of the emphatic intelligence and imagination. CDA, according to Fairclough and Wodak (1997, p. 258), "sees discourse language use in speech or writing - as a form of "social practice. Considering discourse as a social practice demands "a dialectical relationship between a particular discursive event and the situation(s), institution(s) and social structure(s), which frame it" (Fairclough \& Wodak, 1997, p. 258). Considering discourse as a social practice indicated it as constituting "situations, objects of knowledge, and the social identities of and relationships between people and groups of people" (Fairclough \& Wodak, 1997, p. 258).

The role of discourse in any speaking task is ingrained with the emphatic intelligence and imagination as ticking mind and beating heart in the center of oral production. In effect, discourse is constitutive for sustaining and reproducing "the social status quo and transforming it" (Fairclough \& Wodak, 1997, p. 258). Teaching speaking skill involves a kaleidoscopic view in which the type of the relation between and among the interlocutors determine the social relations as a pre-requisite dimension of emphatic intelligence in which the concepts of power, ideology or even hegemony keep changing often and quickly. A kaleidoscopic view needs to be adopted in dealing with speaking skill since any discourse or text is, in fact, the work of a number of interlocutors.

There is no doubt that any language production-written or spoken-involves a vast variety of issues and factors among which intertextuality and recontextualization of diverse genres are brilliant. Meanwhile, diverse models of teaching speaking were introduced dealing with the pronunciation, content, organization, or accuracy; power as "the 
effects of differences in social structures" (Wodak \& Meyer, 2001, p. 10), received the least attention. Wodak and Meyer (2001) argued that "language is entwined in social power in a number of ways: language indexes and expresses power, and is involved where there is contention over and a challenge to power" (p. 10). Hence, considering language as an instrument for exercising power demands a critical discourse analysis perspective regarding teaching any skill including speaking skill since the learners not only needs to be equipped with the integrations of the language but also with the factors other than language influential on the success or failure of any speaking task, i.e. the role played by power, social relations, cultural factors, mediated means, as a few among others.

Emphatic intelligence, on the other hand, as the capacity to make social relationship with others, seems to be crucial for any communication especially the oral ones. In fact, communication means something more than articulating or comprehending some emotions or facts. However, for any communication the interlocutors need to be equipped with the ingredients of language, e.g. lexis, grammar, pronunciation skill, etc.; the empathic intelligence along with imagination seem to be in the heart of communications influencing perception, expression and communication. So many methods have been suggested to meet the diverse challenges the learners experience in dealing with productive skills especially the oral one; but, the emphatic intelligence, the imagination and even the critical thinking skills as the center of any communication have been ignored.

Ioannidou and Konstantikaki (2008) considering empathic intelligence as a foundation on which effective relationship, understanding and communication are constructed argued that effective communication demands "developing ideas and solutions, in problem solving, effective communication and avoiding or preventing conflicts" (p. 119). Accordingly, it is crucial to consider emphatic intelligence as a baseline for teaching speaking skill as a heavily challenging skill the learners need to deal with.

In a nutshell, the results of the study showed significant differences between the performances of the two groups of experimental and control. Hence, the results shed light on the efficacy of the designed innovative model to meet the challenges the foreign language learners go through.

\section{CONCLUSIONS}

The major intent of this study was to design and develop an innovative model for dealing with speaking proficiency in which many challenges the foreign language learners go through be considered. To this end, a number of advanced Iranian students learning English as a foreign language were selected as the participants of the study who were divided into two groups of experimental and control. The both group went under a 120-hour instruction on speaking in which the experimental group using an innovative one and the control group a traditional one were taught. It is worth mentioning that the two groups took a speaking test before instruction to select the most homogenous ones and speaking test after instruction to determine the efficacy of the presented course.

However, the both groups showed a huge learning in terms of speaking proficiency after instruction; the success of the experimental group was much wide. It was found that in teaching speaking skill, a kaleidoscopic view needs to be adopted in terms of the relation between and among the interlocutors in which the social relations seem to be crucial. Furthermore, the study revealed that emphatic intelligence should be considered at the heart of any speaking task. The study also emphasized that the adopted kaleidoscopic view regarding speaking skill needs to consider discourse or text as the work of a number of interlocutors.

\section{REFERENCES}

[1] Arnold, E. (1991). Authenticity revisited: how real is real. English for Specific Purposes 10.3, 237-244.

[2] Arnold, R. (1993). The nature and role of empathy in human development and in drama in education, in Michaels, W.(ed.) Drama in Education: The State of the Art II. Sydney: Educational Drama Association.

[3] Fairclough, N. (1995). Critical discourse analysis. Boston: Addison Wesley.

[4] Fairclough, N. (2001). Critical discourse analysis as a method in social scientific research. In Wodak, R., \& Meyer, M. (Eds), Methods of critical discourse analysis. London: Sage Publications, 121-138.

[5] Fairclough, N. and Wodak, R. (1997). Critical discourse analysis, In T. van Dijk (ed.), Discourse Studies: A Multidisciplinary Introduction. London: Sage, pp. 258-84.

[6] Fowler, R. \& Kress, G. (1979). Critical linguistics. In Fowler, R., Hodge, B., Kress, G. \& Trew, T. (Eds). Language and control. London: Rutledge and Keegan Paul, 185-213

[7] Halliday, M. A. K. (1970). Language as social semiotic. London: Edward Arnold.

[8] Halliday, M. A. K. (1985). An introduction to functional grammar. London: Edward Arnold.

[9] Ioannidou, F. \& Konstantikaki, V. (2008). Empathy and emotional intelligence: What is it really about? International Journal of Caring Sciences 1. 3, 118-123.

[10] Jager, S. (2001). Discourse and knowledge: Theoretical and methodological aspects of a critical discourse and dispositive analysis. In Wodak, R., \& Meyer, M. (Eds), Methods of critical discourse analysis. London: Sage Publications, 39-62.

[11] Luoma, Sari. (2004). Assessing speaking. Cambridge: Cambridge University Press.

[12] McCarthy, M. J., \& Carter, R. A. (1997). Grammar, tails and affect: Constructing expressive choices in discourse. Text 17, 405-429.

[13] Meyer, M. (2001). Between theory, method and politics: Positioning of the approaches to CDA. In Wodak, R., \& Meyer, M. (Eds), Methods of critical discourse analysis . London: Sage Publications, 14-31. 
[14] Rahimi, A., \& Sahragard, R. (2007). Critical discourse analysis. Tehran: Jungle Publications.

[15] Richards, J. C. (1990). Conversationally Speaking: Approaches to the Teaching of Conversation. The Language Teaching Matrix. Cambridge: Cambridge University Press.

[16] Scollon, R. (2001). Action and text: towards an integrated understanding of the place of text in social (inter)action, mediated discourse analysis and the problem of social action. In Wodak, R., \& Meyer, M. (Eds), Methods of critical discourse analysis. London: Sage Publications, 141-183.

[17] Van Dijk, T. (2001). Multidisciplinary CDA: A place for diversity. In Wodak, R., \& Meyer, M. (Eds), Methods of critical discourse analysis. London: Sage Publications, 95-120.

[18] Weiss, G., \& Wodak, R. (2003). Critical discourse analysis: Theory and interdisciplinarity. New York: Palgrave Macmillan.

[19] Wodak, R. (2001). What CDA is about - a summary of its history, important concepts and its developments. In Wodak, R., \& Meyer, M. (Eds), Methods of critical discourse analysis. London: Sage Publications, 1-13.

[20] Wodak, R. (2002). Aspects of critical discourse analysis. ZfAL 36, 5-31.

[21] Wodak, R. (2007). Pragmatics and critical discourse analysis. http://www.essex.ac.uk/centres/TheoStud/pragmcognitionwodak2007.pdf (accessed 24/01/2010).

Fateme Esmaili was born in Shiraz, Islamic Republic of Iran. She completed her master' degree in TEFL at the University of Arak in 2011; and holds a BA degree in English Translation. She has taught English at different levels and ESP courses for seven years. She has presented a great number of papers on the domain of education in many national and international conferences. She is currently an advisor as well as an instructor at Farda Language Center (FLC) and Virtual Academy of Foreign Languages (VAFL). Her academic research mainly focuses on critical discourse analysis and applied linguistics along with Sociolinguistics, semantics and pragmatics.

Somaye Hamdi Asl was born in Abadan, Islamic Republic of Iran. She obtained her master's degree in TESOL at IAU in Najafabad, Iran in 2012, and holds a BA degree in English Translation. She has worked as an English instructor as well as an interpreter for seven years. She is currently working as an English instructor at some language institutes and also as an interpreter at National Iranian Oil Company. Her research interests include discourse analysis as well as teaching and teachers' education.

Elham Farahani has an M.A. in TEFL from Arak University, Iran. She is currently a visiting lecturer in the Department of English Language at Mofid University, Iran. Her fields of interest include: CDA, discourse analysis, corpus linguistics, EAP, and second language writing. She has published and presented a number of papers in international journals and conferences on critical discourse analysis and ELT. 